\title{
The effect of low oxygen uptake rate on the fatty acid profile of the oleaginous yeast Apiotrichum curvatum
}

\section{R. Julian Davies, Jane E. Holdsworth, and Sarah L. Reader}

Biotechnology Group, Industrial Processing, Department of Scientific and Industrial Research, PO Box 31-310, Lower Hutt, New Zealand

Applied Microbiol Biotechnol (1990) 33:569-573

The oxygen uptake rate equation quoted in the above article is incorrect. The correct equation is:

$$
\text { OUR }=\frac{60,000 \times \text { airflow }}{22.4 \times V \times 100} \times\left[20.95-\% O_{2_{\text {our }}}\left(\frac{78.9}{100-\% O_{2_{\text {out }}}-\% \mathrm{CO}_{2_{\text {out }}}}\right)\right]
$$

The corrected values for OUR are not dissimilar to those reported in the paper and our conclusions still remain the same.

Corrected values for OUR are included as follows in Tables 1,2 and 3.

Table 1. Effect of varying oxygen uptake rate (OUR) on the growth and lipid production of Apiotrichum curvatum ATCC 20509 in a 20-1 fermentor

\begin{tabular}{|c|c|c|c|c|c|c|c|c|c|c|}
\hline \multirow{2}{*}{$\begin{array}{l}\text { Run } \\
\text { no. }\end{array}$} & \multicolumn{2}{|c|}{ Air-flow rate (SLPM) } & \multirow{2}{*}{$\begin{array}{l}\text { Time after } \\
\text { inoculation } \\
\text { when air } \\
\text { decreased } \\
\text { (h) }\end{array}$} & \multirow{2}{*}{$\begin{array}{l}\text { Ferment- } \\
\text { ation } \\
\text { time } \\
\text { (h) }\end{array}$} & \multirow{2}{*}{$\begin{array}{l}\text { OUR } \\
(\mathrm{mmol} / \mathrm{l} / \mathrm{h})\end{array}$} & \multirow{2}{*}{$\begin{array}{l}\text { Oil } \\
\text { coefficient }\end{array}$} & \multicolumn{2}{|c|}{ Lactose $(\mathrm{g} / \mathrm{l})$} & \multirow{2}{*}{$\begin{array}{l}\text { Biomass yield } \\
\text { g dry cells/ } \\
\text { g lactose } \\
\text { utilised }\end{array}$} & \multirow{2}{*}{$\begin{array}{l}\text { Lipid } \\
\text { content } \\
\%(w / w)\end{array}$} \\
\hline & $\begin{array}{l}\text { Growth } \\
\text { phase }\end{array}$ & $\begin{array}{l}\text { Oil } \\
\text { accumulation } \\
\text { phase }\end{array}$ & & & & & Initial & Final & & \\
\hline 1 & 14.0 & 4.0 & 25 & 120 & 2.2 & 0.15 & 39.9 & 0.6 & 0.33 & 41.4 \\
\hline 2 & 12.5 & 5.0 & 18 & 41 & 2.4 & 0.12 & 37.8 & 17.5 & 0.28 & 29.8 \\
\hline 5 & 14.0 & 6.0 & 17.0 & 41 & 6.5 & 0.17 & 26.4 & 3.8 & 0.31 & 42.4 \\
\hline 6 & 16.0 & 9.0 & 21.0 & 67 & 7.1 & 0.19 & 29.7 & 0.3 & 0.47 & 37.6 \\
\hline 7 & 16.0 & 16.0 & - & 40 & $\begin{array}{l}\text { Varying } \\
8-10\end{array}$ & 0.21 & 30.4 & 0.1 & 0.54 & 39.0 \\
\hline
\end{tabular}



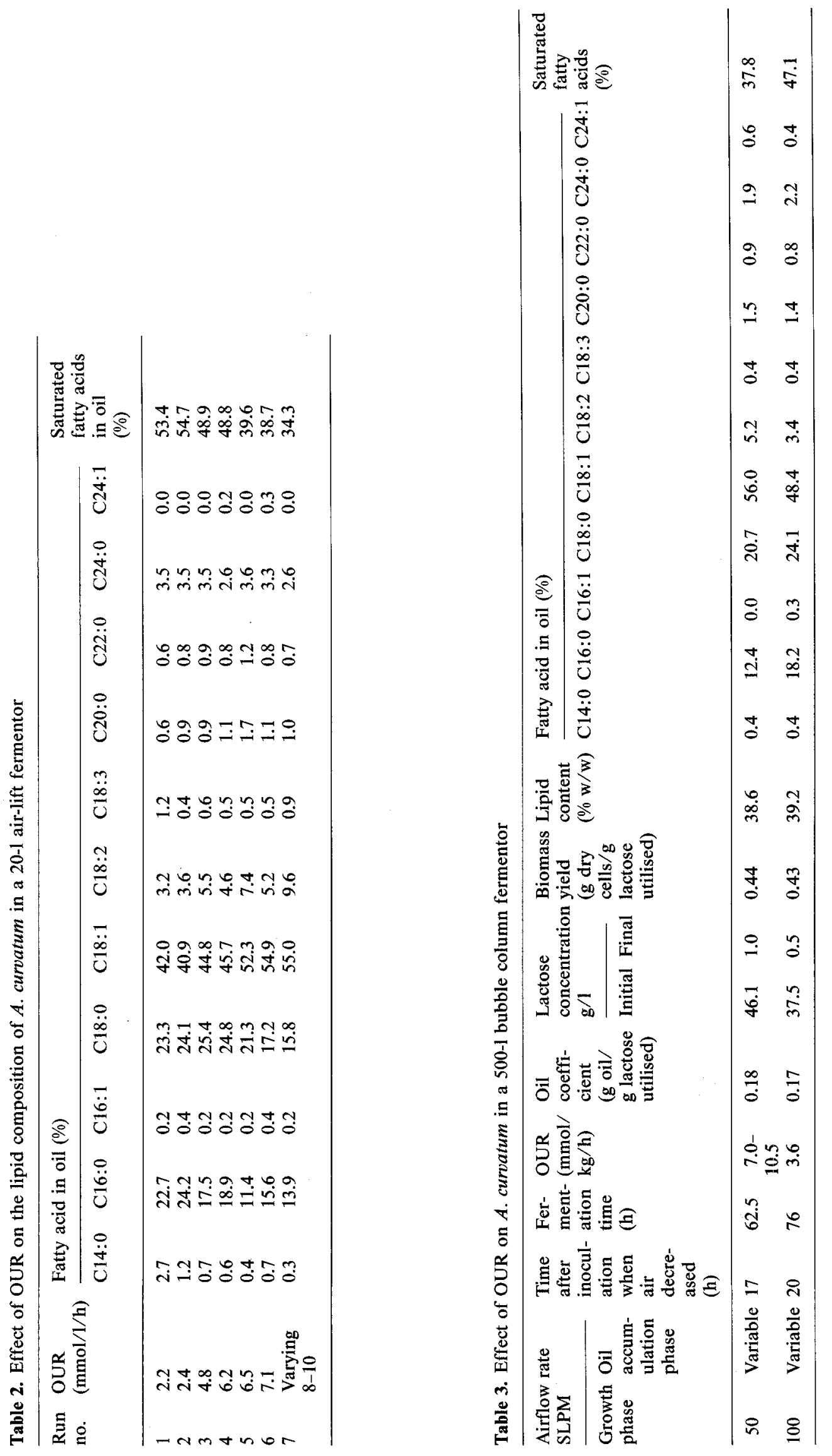